\title{
Incorporation of Zinc Oxide into Carbon nanotube/Graphite nanofiber as high performance supercapacitor electrode
}

\begin{abstract}
An efficient and simple hydrothermal method has been developed to prepare Carbon nanotube/Graphite nanofiber/Zinc Oxide (CNT/GNF/ZnO) ternary composites which are employed as supercapacitor materials. The electrochemical measurements reveal that the introduction of $\mathrm{ZnO}$ into $\mathrm{CNT} / \mathrm{GNF}$ can enhance the specific capacitance value up to 306 $\mathrm{Fg}^{-1}$ at $10 \mathrm{mVs}^{-} 1$, with $99.4 \%$ capacity retention. Field-emission scanning electron microscopy (FESEM) and transmission electron microscopy (TEM) characterizations reveal that the combination of nanometer-sized CNT/GNF and random distribution of impregnated $\mathrm{ZnO}$ can form a highly conductive network. The improved supercapacitance property of $\mathrm{CNT} / \mathrm{GNF} / \mathrm{ZnO}$ can be ascribed to the synergistic effect between double layer capacitance of $\mathrm{CNT} / \mathrm{GNF}$ and the pseudocapacitance of $\mathrm{ZnO}$.
\end{abstract}

Keyword: CNT; GNF; Supercapacitors; Physicochemical; Electrochemical characterization 